\title{
Advanced Joining Technologies for Load and Fibre Adjusted FRP-Metal Hybrid Structures
}

\author{
M. Klein ${ }^{1}$, F. Podlesak ${ }^{2}$, K. Höfer ${ }^{2}$, H. Seidlitz ${ }^{1}$, C. Gerstenberger ${ }^{1}$, P. Mayr ${ }^{2} \&$ L. Kroll ${ }^{1}$ \\ ${ }^{1}$ Lightweight Structures and Polymer Technology, TU Chemnitz, Chemnitz, Germany \\ ${ }^{2}$ Welding Engineering, TU Chemnitz, Chemnitz, Germany \\ Correspondence: M. Klein, Lightweight Structures and Polymer Technology, Chemnitz University of Technology, \\ Chemnitz, Germany. Tel: 49-371-5313-4219. E-mail: mario.klein@mb.tu-chemnitz.de
}

Received: July 15, 2015 Accepted: July 28, 2015 Online Published: August 13, 2015

doi:10.5539/jmsr.v4n4p26 URL: http://dx.doi.org/10.5539/jmsr.v4n4p26

\begin{abstract}
Multi-material-design (MMD) is commonly realized through the combination of thin sheet metal and fibre reinforced plastics (FRP). To maximize the high lightweight potential of the material groups within a multi-material system as good as possible, a material-adapted and particularly fibre adjusted joining technology must be applied. The present paper focuses on two novel joining technologies, the Flow Drill Joining (FDJ) method and Spin-Blind-Riveting (SBR), which were developed for joining heavy-duty metal/composite hybrids. Tests were carried out with material combinations which are significant for lightweight constructions such as aluminium (AA5083) and carbon fibre-reinforced polyamide in sheet thickness of $1.8 \mathrm{~mm}$. The mechanical testing and manufacturing of those multi-material joints was investigated.
\end{abstract}

Keywords: multi-material design, fibre reinforced plastics, lightweight automotive structures, joining

\section{Introduction}

Load-path adapted multi material design initiates significant mass reduction in automotive industry and contributes to resource savings. The combined use of metal sheets and fibre-reinforced plastic (FRP) offers a very high lightweight potential (Klein, 1997; Rosato, 2005; Goede et al., 2010) through all the material groups. For a uniform initiation of concentrated loads usually metal components are applied. In contrast to that FRPs are more suitable for load transmission along large distances (Schürmann, 2005; Kroll, 2009).

Due to comparatively short cycle times when manufacturing components and the use of inexpensive matrix systems such as polypropylene, but also higher-quality plastics such as polyamide or polyether ether ketone, the use of thermoplastic FRPs with high strength and stiffness properties has raised significantly through the last years.

The demand on car bodies to become lighter and more efficient lead to massive development in sheet metal production. Not only steel manufacturers presented high strength steel qualities, but also aluminium and magnesium gained influence in automotive applications. Therefore, the task for advanced joining technologies is to offer a wide range of processable materials in both categories, FRP and metal. Through the combined use of thermoplastic FRPs and thin-walled metal sheets or extrusions, the modern body in white consists of weight-optimized components especially developed for vehicle construction. To solve this, the required joining technology takes a central role within the manufacturing process.

The joining technology for thin-walled structural components, made of FRP and metal sheets, is considered to be extremely challenging. Primarily mechanical methods such as screwing, blind and punch riveting as well as hybrid techniques are applicable (Simon, 2005) due to the strongly different thermo-mechanical behaviour and the divergent material composition and morphology.

Furthermore the conventional placing of joining elements leads to a sectioning of load bearing fibres at the load initiation zone of the FRP. As a consequence, high notch stresses are induced, which weaken the FRP component significantly and prevent the optimal exploitation of the high anisotropic lightweight potential (Colins, 2006; Seidlitz et al., 2011). Therefore additional reinforcements like cones and patches are applied at critical notch stress areas, which consequently lead to a strong over-sizing of the joint, an increased component weight and most of all space problems. To fully exploit the high anisotropic material behaviour of the FRP, the joining process must be performed very gentle as well as load path adapted (Rotheiser, 2009). 
This paper focuses on the qualification of the new flow-drill joining (FDJ) concept and the Spin-Blind-Riveting (SBR) concept - showing potentials and references for automotive application. The technologies are currently used to join plane metal sheets and thermoplastic FRPs within wall thickness range of 1.0 to $4.0 \mathrm{~mm}$ (Seidlitz, 2013b). In analogy to bionic, the fibres can be aligned along the force flux lines at the joint of the FRP component. With these new technologies, it is possible to join different materials without the need of predrilling. Therefore, a minimum preparation effort and less destruction of fibres can be guaranteed.

\section{Methods}

\subsection{Flow Drill Joining Concept}

The flow drill joining (FDJ) concept was developed at the Institute of Lightweight Construction at Chemnitz University of Technology. It primarily serves to join comparatively thicker thermoplastic FRPs with metal sheets. The process is characterized by short processing times and high-strength joining properties appropriate for the force fluxes. The high degree of lightweight construction and can be utilized in various industrial sectors, not only automotive, but also space and aviation. The essential advantage towards typical joining technologies relates to the fact that no additional auxiliary joining elements are needed for joining the components.

In order to manufacture an FDJ joint, the plastic flow properties of the metal component are reduced due to heat influence. With the use of a rotating mandrel, a bushing is thermo-mechanically shaped from the metallic base material. While doing so, this bushing is pushed directly through the also locally plasticized thermoplastic FRP component during the shaping operation and is subsequently pulled over in a positive-locking form when the mandrel is retracted or in an additional working step (Figure 1). The rotation of the mandrel and the associated friction serve to release thermal energy which is locally introduced into the FRP component as a result of the process and thus initiates the partial melting of the thermoplastic matrix. Therefore, the continuous fibres arranged in the plastic become "moveable" and can be aligned towards the force fluxes during the shaping of the bushing (Seidlitz et al., 2011).

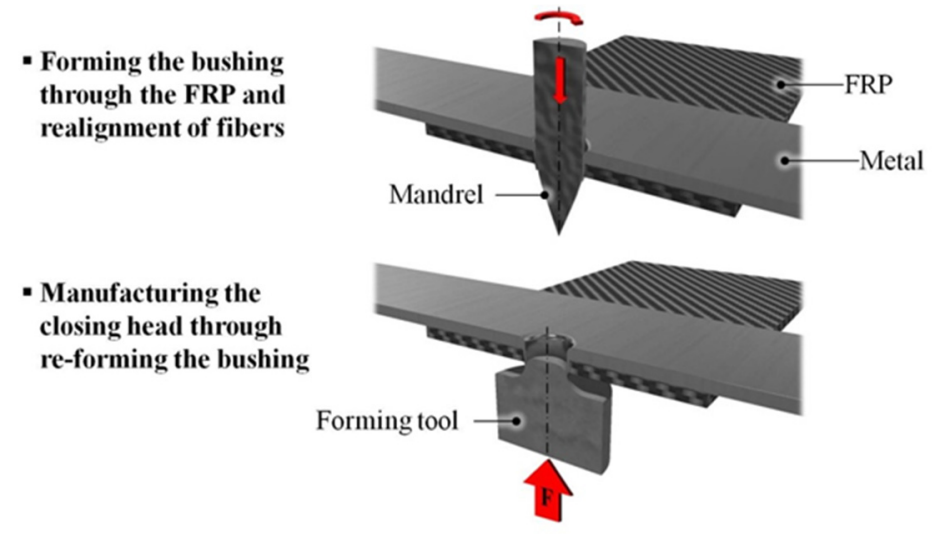

Figure 1. Process scheme for manufacturing FDJ joints (Seidlitz et al., 2011)

\subsection{Spin Blind Riveting (SBR)}

Spin-Blind-Riveting (SBR) has its origin in conventional blind riveting, which is a common solution to join different materials (Nestler, 2013). Additionally, SBR uses the effects of flow drilling as described in (Biermann, 2014) and the effects of hole moulding (Hufenbach, 2009). Main difference is that SBR uses a modified blind rivet as tool and joint element at the same time. In contrast to conventional riveting, no predrilling is necessary and the process is completely free of chip formation. SBR principle is illustrated in Figure 1.

A metal and a FRP sheet are placed as lap joint with the metal sheet on the upside. A blind rivet with a conical mandrel head is rotated and pressed onto the sheets with a force. Due to rotation and pressure, the metal sheet begins to locally heat up and plastify under the rivet. Thus the rivet penetrates into the metal sheet under formation of a sleeve similar to flow drilling. The formed sleeve is pushed into the FRP sheet and because of the frictional heat between rivet and metal sheet the thermoplastic matrix of the FRP is also heated up and locally melted by conduction. When the rivet is fully penetrated through both sheets, the mandrel is pulled back and the rivet head forms into the blind-head of the rivet body. With this formation of joint the sheets are additionally pressed together and the melted matrix of the FRP is cooling down and adheres partially at the metal sheet. 


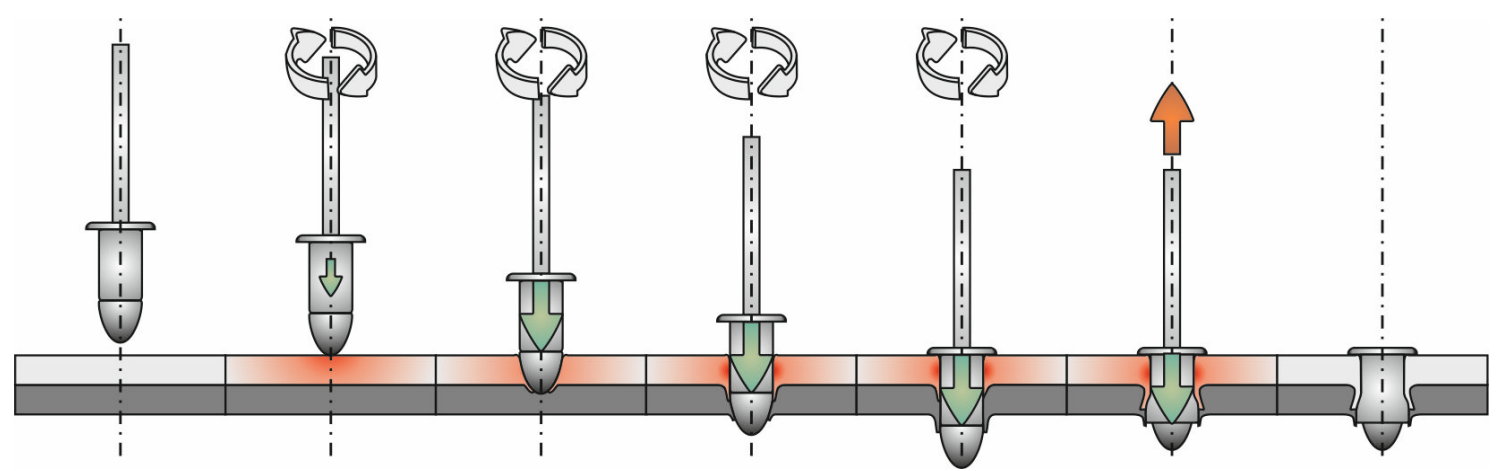

Figure 2. Process scheme for manufacturing SBR joints

Main process parameters are:

- Rivet geometry

- Rotation speed of rivet

- Penetration force

One specific property of the joint is the formation of a sleeve due to material displacement in the upper sheet. This sleeve can transmit significantly higher shear loads than conventional rivet joints. Furthermore SBR causes less damage at the fibres of reinforced plastic sheets because the material is heated up above the glass transition temperature of the thermoplastic matrix and fibres can be displaced instead of destroying them like as with drilling

\section{Experimental Setup}

\subsection{Materials Studied}

Organic sheets are flat semi-finished products made of thermoplastic FRP's, which can be prepared by stacking of unidirectional (UD) pre-impregnated layers (prepregs). Subsequent pressing at matrix melting temperature (for polyamide 6: $220^{\circ} \mathrm{C}$ ) produces the final product. These thermo formable unidirectional and multidirectional composite structures with defined mechanical properties can be produced within short cycle times. Similar processing chains as for metal sheet forming are aplicable. Furthermore, in addition to the high specific strength and stiffness properties, thermoplastic FRP's possess comparatively high damping characteristics, good crash resistance as well as material immanent recycling properties. Subject matter of the investigations are FRPs with orthotropic carbon fibre reinforcement, embedded in a polyamide 6 (PA 6) matrix system. Table 2 gives an overview referring to the applied unidirectional (UD) prepreg systems, laminate lay-up and further specific properties.

Table 1. Properties of metallic joining partners

\begin{tabular}{lcccc}
\hline material & young's modulus & tensile strength & yield strength & thickness \\
\hline Aluminium & & & & \\
AlMg4.5Mn & $71 \mathrm{GPa}$ & $300 \mathrm{MPa}$ & $125 \mathrm{MPa}$ & $1,5 \mathrm{~mm}$ \\
(AW5083) & & & & \\
\hline
\end{tabular}

Table 2. Properties of CFRP joining partners

\begin{tabular}{lcccccc}
\hline FRP type & prepreg & lay up & $\begin{array}{c}\text { young's modulus } \\
\mathrm{E}_{1}=\mathrm{E}_{2}\end{array}$ & $\begin{array}{c}\text { tensile strength } \\
\sigma_{1}=\sigma_{2}\end{array}$ & fibre volume ratio & thickness \\
\hline CFRP & $\begin{array}{c}\text { UD carbon fibre } \\
\text { /PA 6 (Ticona) }\end{array}$ & {$\left[(0 / 90)_{3}\right]_{\mathrm{s}}$} & $49.5 \mathrm{GPa}$ & $860 \mathrm{MPa}$ & 0.6 & $1.8 \mathrm{~mm}$ \\
\hline
\end{tabular}




\subsection{Experimental Setup}

Material combinations were joined by both processes, FDJ and SBR according to DIN EN ISO 14273 as tensile shear test specimens with a length of $175 \mathrm{~mm}$, width of $50 \mathrm{~mm}$ and an overlapping length of $35 \mathrm{~mm}$.

The described FDJ process was carried out by an automated joining jig (Figure 3 left). Joining of the comparatively thick walled CFRP components was supported by an infrared heating system, which plasticizes the matrix component efficiently within a short processing time.

The SBR riveting process is based on a conventional blind riveting tool but due to reasons of simplicity, the specimen rotates instead of the rivet. The joining force is induced by a pneumatic cylinder. Parameter settings are modified by a programmable control unit. In further work a rivet-setting tool will be developed, which combines the rotation of the blind rivet to penetrate the sleeves and afterwards the forming of the rivet by backwards movement. Both experimental setups are shown in Figure 3 (right).
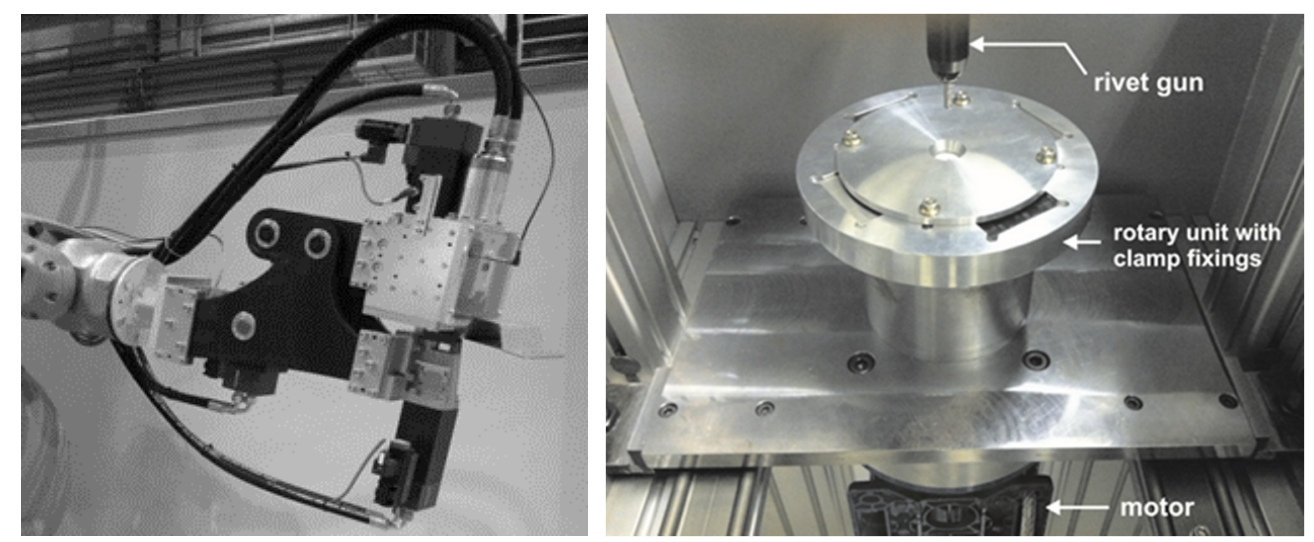

Figure 3. Left: Joining jig for FDJ process; Right: SBR experimental

In Figure 4 (right) a macro section of the used rivet developed by Gesipa Blindnietgeräte GmbH is shown. The mandrel head consists of steel and has a conical shape. In the left image of Figure 4 the geometric properties of mandrel for the FDJ process are shown. The applied joining point diameter of $5.3 \mathrm{~mm}$ for FDJ and $4.8 \mathrm{~mm}$ for SBR were chosen, since most of the mechanical joints in actual body in white structures show similar geometric parameters. Table 3 summarizes the processing parameters and shows exemplarily samples of the manufactured joints.

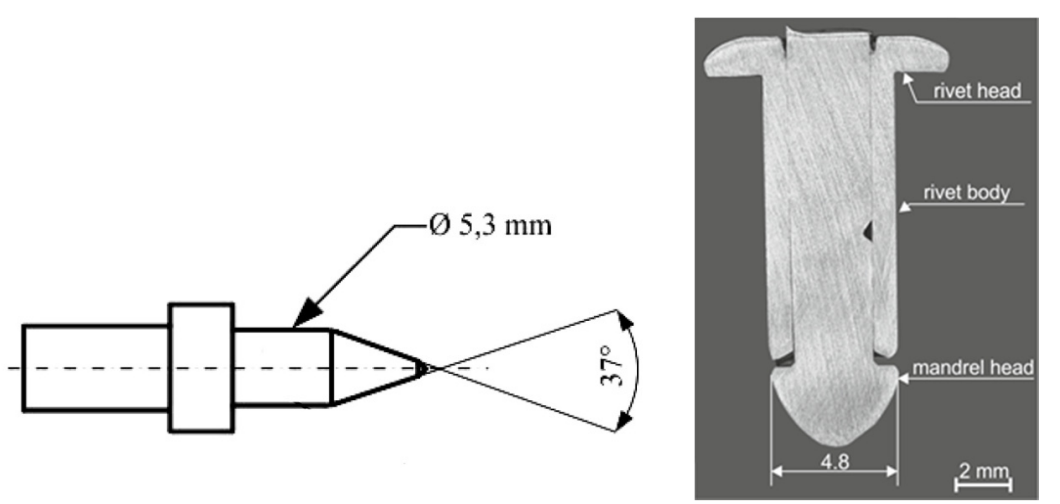

Figure 4. Left: Mandrel for the FDJ process; Right: Rivet used for SBR process

Following experimental investigations were carried out:

- Evaluation of process characteristics

- Visual evaluation

- Mechanical testing 
Table 3. Manufactured FDJ / SBR joints and parameters

\begin{tabular}{lc}
\hline Tensile shear specimen & Processing parameters \\
\hline & Joining point diameter: $5.3 \mathrm{~mm}$ \\
AlMg4.5Mn/CFRP (FDJ) & Joining force: $20 \mathrm{kN}$ \\
(Number of specimens: 5) & Flow drill speed: $3000 / \mathrm{min}$ \\
& Heating time: $14 \mathrm{~s}$ \\
\hline & Joining point diameter: $4.8 \mathrm{~mm}$ \\
AlMg4.5Mn/CFRP (SBR) & Joining force: $3 \mathrm{kN}$ \\
(Number of specimens: 5) & Rotation speed: $4200 / \mathrm{min}$ \\
& Penetration time: $2 \mathrm{~s}$ \\
\hline
\end{tabular}

At first, specimens were joined with the parameters given in Tab. 1 for visual evaluation. For this, the specimens were viewed and macro sections were made.

At least five specimens per process were joined for shear load tests. Shear tension test were done with an elongation speed of $1 \mathrm{~mm} / \mathrm{min}$ with a Zwick Z050.

Beneath the comparison of the load values, the fracture behaviour was analysed. Especially failure mode and location indicates the quality of the joint.

\section{Results and Discussion}

The obtained material combinations were joined successfully by both processes, FDJ and SBR. Images of joint samples are shown in Fig. 5. While the upper side of the SBR joint looks similar to a conventional blind rivet joint, the down side shows the formation of a sleeve and the mandrel head has annealing colours because of the frictional heat. The FDJ joint shows a zone with melted CFRP and a sleeve formation in the metal sheet which is completely penetrated through the CFRP. It also can be seen, that at both processes, some of the fibres of the CFRP are deflected and some are destroyed due to high deformation degrees. Altogether both processes lead to joints with a high optical appearance.
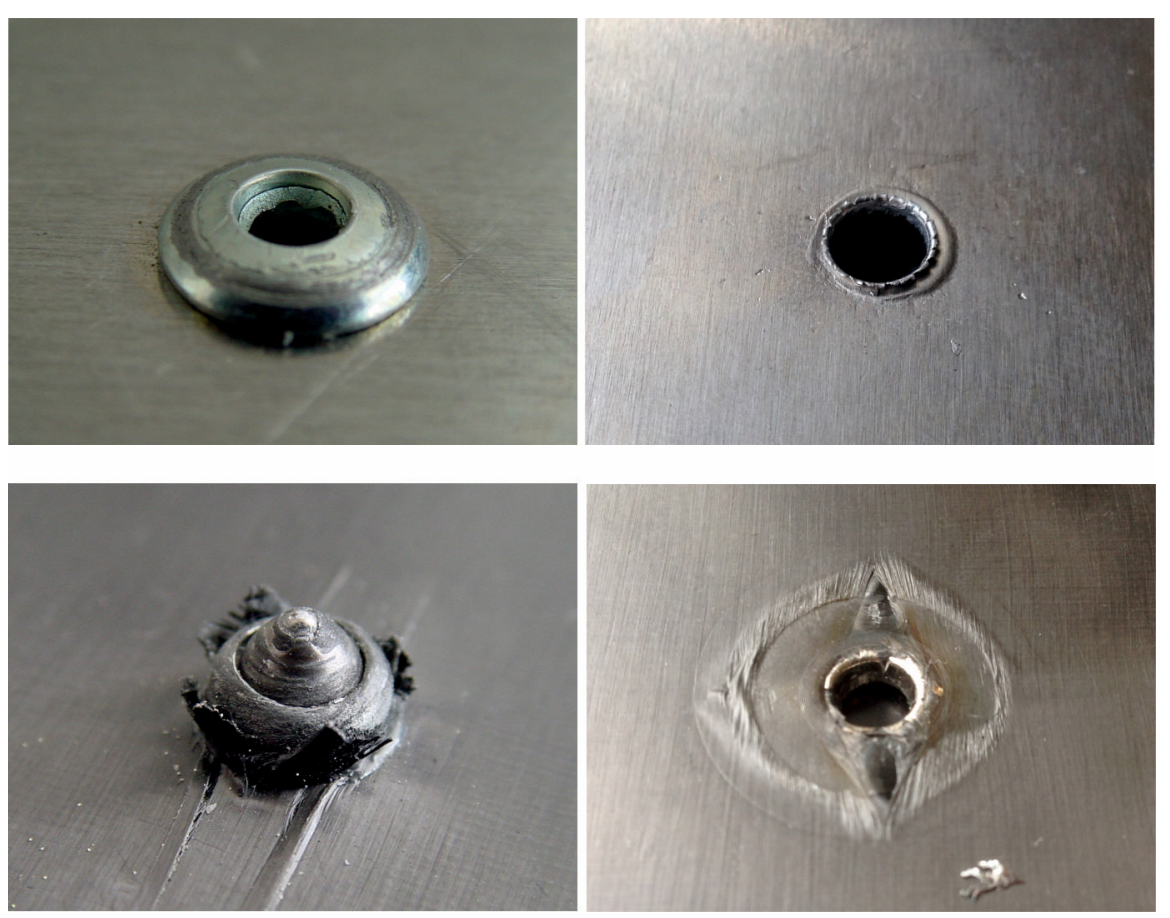

Figure 5. Left: Joint made by SBR process; right: Joint made by FDJ process, upper photos show the metal side, bottom photos show the FRP side of the joint 
In Figure 6, macro sections are shown. It can be seen that both processes form a sleeve in joining direction without any chip formation. They have almost the same dimensions in terms of diameter, wall thickness and length. Most of the metal material is displaced to the downside of the sheet while only a minor part is displaced to the upside. The sleeves, formed by FDJ and SBR are pushed completely through the CFRP. While the form lock is established by the rivet at the SBR process, it is made by the sleeve itself at the FDJ process through the forming tool (Figure 1). The macro sections also show that the CFRP is locally melted by the processes und the fibres are deflected at the joining zone without signs of failures like delamination.
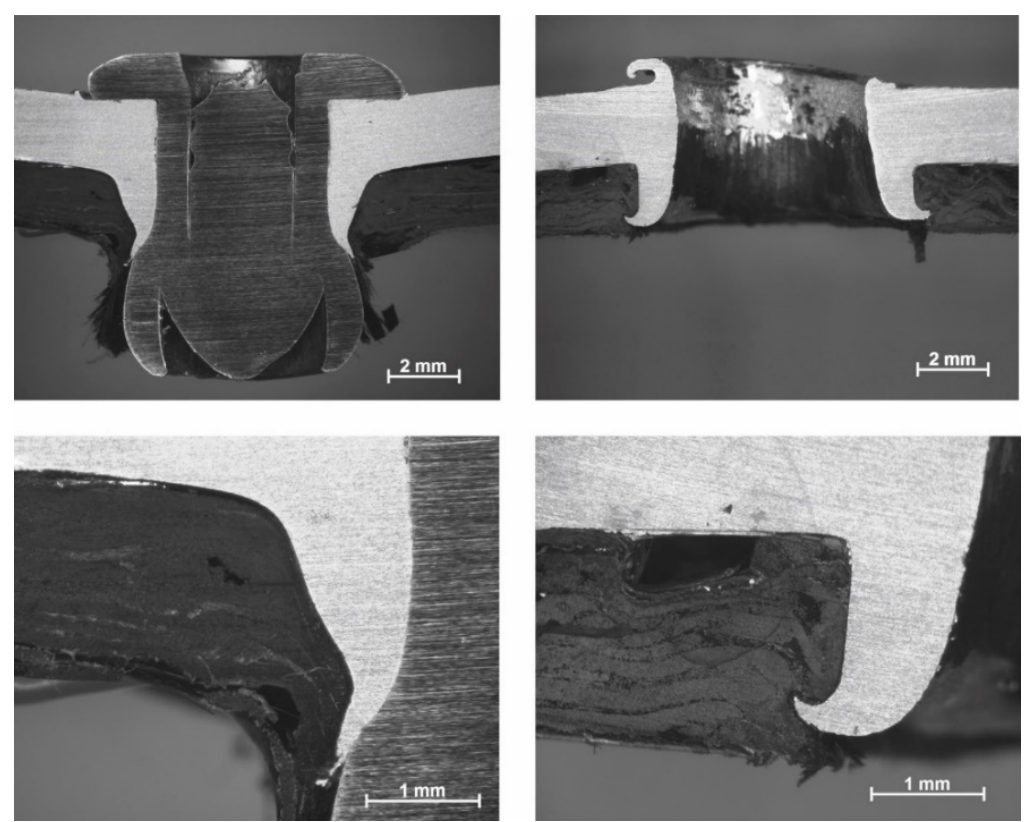

Figure 6. Macro sections; Left: SBR process; right: FDJ process

Characteristic force-displacement curves under shear tension for both processes, FDJ and SBR are shown in Figure 7. As it can be seen shear load curves of all specimens have a linear characteristic at lower load values and a peak value at the end of this linear characteristic at about $2.3 \mathrm{kN}$. The subsequent values vary greatly and peak loads between 2.3 and $3.1 \mathrm{kN}$ are achieved. The failure mode is a mixture of bearing and pull-out failure. By reaching a load level of $2.3 \mathrm{kN}$ the metal sheet deforms and instead of a pure shear load, a combined load appears. Under these conditions, the SBR joints show slightly higher values than the FDJ joints because the rivet can take up the combined load better than the sleeve of the FDJ joint. All together both kinds of joint processes show good results and a low standard deviation under pure shear load.

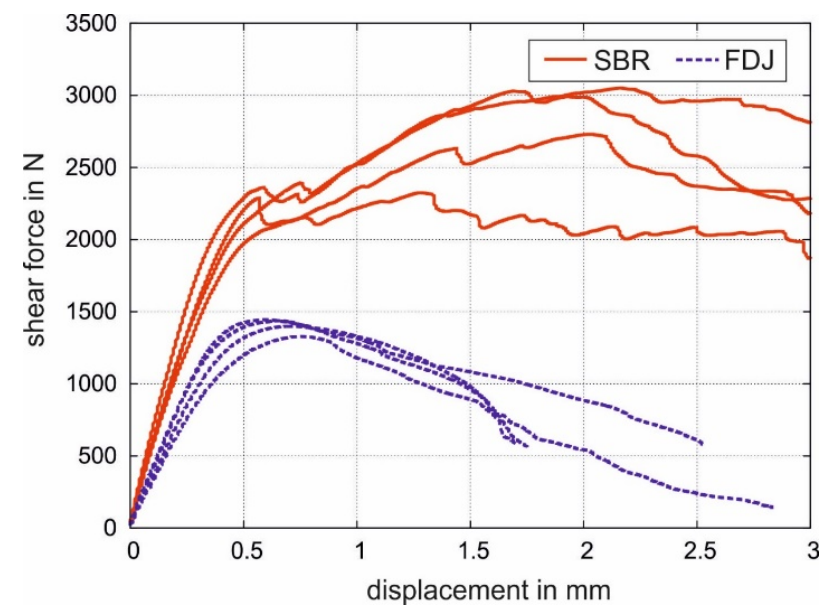

Figure 7. Force-displacement curves for SBR and FDJ joined specimens 
Additionally attention should be paid on the weight of every joint with regard to applications in lightweight constructions. While the FDJ joint does not cause any extra weight, the SBR joint causes an extra weight of about $2.2 \mathrm{~g}$ per joint due to the inserted rivet.

\section{Conclusions}

- Two high promising processes for easy and high strength joining of metals to fibre reinforced plastics were developed. A combination of aluminium sheets and CFRP sheets were joined successfully.

- Both processes show short cycle times and a good repeatability.

- Both processes form a uniform sleeve in the metal sheet which can support shear loads. The fibres in the CFRP are partly deflected and only a minor part is destroyed which causes less damage than comparable processes with predrilling.

- The joints show good strength properties so this process becomes attractive for use in applications with high demands in reliability and strength.

- SBR joints show slightly higher shear load values than FDJ joints while these causes less extra weight.

\section{Acknowledgements}

This research project was supported by the European Social Fund and Sächsische Aufbaubank (Antragsnummer 100110153).

The publication costs of this article were funded by the German Research Foundation/DFG (Geschäftszeichen INST 270/219-1) and the Chemnitz University of Technology in the funding programme Open Access Publishing.

\section{References}

Biermann, D., \& Liu, Y. (2014). Innovative Flow Drilling on Magnesium Wrought Alloy AZ31. Proceedings of the International Conference on Manufacturing of Lightweight Components - ManuLight 2014, 18, 209-214. http://dx.doi.org/10.1016/j.procir.2014.06.133

Collins, M. W., \& Brebbia, C. A. (2006). Design and Nature II: Comparing Design in Nature with Science and Engineering (6th ed.). Southampton: WIT Press. http://dx.doi.org/10.1086/431108

Döhler, C., Hälsig, A., Podlesak, H., Czech, A., Nestler, D., Wielage, B., .. Kroll, L. (2014). Energy-Efficient Joining Technologies to Realise Dissimilar Joints of Metal and Fibre-Reinforced Plastics. In R. Neugebauer \& W. G. Drossel (Ed.), 3rd ICMC 2014 - International Chemnitz Manufacturing Colloquium/3rd International Colloquium of the Cluster of Excellence eniPROD Part 1 Innovations of Sustainable Production for Green Mobility (Vol. 80, pp. 447-459). Chemnitz, Germany: Fraunhofer-Institut für Werkzeugmaschinen und Umformtechnik IWU. http://dx.doi.org/10.1002/mawe.201000629

Goede, M., Stehlin, M., Rafflenbeul, L., Kopp, G., \& Beeh, E. (2009). Super Light Car-lightweight construction thanks to a multi-material design and function integration. European Transport Research Review, 1, 5-10. http://dx.doi.org/10.1007/s12544-008-0001-2

Hufenbach, W., Gottwald, R., \& Kupfer, R. (2009). Bolded joints with moulded holes for textile thermoplastic composites. 18th International Conference on Composite Materials.

Ind.Exp. (2013). Carbon Fibres \& Carbon Reinforced Plastics (CFRP) - A Global Market Overview. London: Industry Experts.

Kroll, L. (2009). Textilverstärkte Kunststoffbauteile in funktionsintegrierender Leichtbauweise. In E. Wintermantel, S.-W. Ha (Ed.), Medizintechnik: Life Science Engineering (Vol. 5, pp. 343 - 356). Berlin Heidelberg, Germany: Springer. http://dx.doi.org/10.1007/978-3-540-93936-8_15

Malikova, V., Ossenbrink, R., Viehweger, B., \& Michailov, V. (2013). Experimental study of the change of stiffness properties during deep drawing of structured sheet metal. Journal of Materials Processing Technology, 11, 1811-1817. http://dx.doi.org/doi:10.1016/j.jmatprotec.2013.05.005

Rosato, D. V. (2005). Reinforced Plastics Handbook (3rd Ed.). Oxford: Elsevier Advanced Technology. http://dx.doi.org/10.1016/b978-185617450-3/50005-0

Rotheiser, J. (2009). Joining of Plastics - Handbook for Designers and Engineers (3rd Ed.). Munich: Carl Hanser Verlag, http://dx.doi.org/10.3139/9783446445956

Seidlitz, H., Kroll, L., \& Ulke, L (2009). Load adjusted joining technology for Composite-Metal Hybrids. In T. Burczyński, W. Cholewa, \& W. Moczulski (Ed.), Methods of Artificial Intelligence (pp. 51-52). Gliwice, Poland: Silesian University of Technology. Faculty of Mechanical Engineering. Department of Fundamentals of Machinery Design. 
Seidlitz, H., Ulke, L., \& Kroll, L. (2013, January 31). DE 102009013265B4: Methods and tools for producing a mixed module. Chemnitz University of Technology.

Seidlitz, H., Ulke, L., Gerstenberger, C., \& Kroll, L. (2013). Dimensioning of Punctiform Metal-Composite Joints: A Section-Force Related Failure Criterion. Munich: Open Journal of Composite Materials. http://dx.doi.org/ 10.4236/ojcm.2014.43018

Viehweger, B., Simon, S., Wagner, L., \& Berg, A. (2002). Aluminium - Stahl - Verbundblech. In VDI-Gesellschaft Fahrzeug- und Verkehrstechnik, Entwicklungen im Karosseriebau - Development in Chassis Engineering (VDI-Berichte Nr. 1674) (pp. 377 - 384). Düsseldorf, Germany: VDI Verlag.

\section{Copyrights}

Copyright for this article is retained by the author(s), with first publication rights granted to the journal.

This is an open-access article distributed under the terms and conditions of the Creative Commons Attribution license (http://creativecommons.org/licenses/by/3.0/). 